\title{
The Application of Innovative Automobile Maintenance Services from Customers' Viewpoints: A Hybrid Method*
}

\author{
Ching-Fang Lee ${ }^{1}$, Chien-Ping Chung ${ }^{2}$ \\ ${ }^{1}$ Department of Marketing and Logistics, Ming Dao University, Changhua County, Taiwan \\ ${ }^{2}$ Department of Business Innovation and Development, Ming Dao University, Changhua County, Taiwan \\ Email: chingfanglee@mdu.edu.tw, cpc@mdu.edu.tw
}

Received September 3, 2013; revised October 7, 2013; accepted October 29, 2013

Copyright (C) 2013 Ching-Fang Lee, Chien-Ping Chung. This is an open access article distributed under the Creative Commons Attribution License, which permits unrestricted use, distribution, and reproduction in any medium, provided the original work is properly cited.

\begin{abstract}
Company experts and academicians have paid significant attention to issues of new product/service development. However, few studies have been carried out to discuss innovative product/service development mindful of the competitive positions between competitors. This study introduces a hybrid method of positioning analysis, conjoint analysis and rough set theory to understand the competition positions and facilitate innovative product/service development from the customers' perspective. The hybrid method is also supported by in-depth interviewing, factor analysis, preference regression, ideas simulation, ideas selection, and specific weight valuation methods. We choose the automobile maintenance industry in Taiwan, whose objective is to improve product/service qualities and enhance customers' satisfaction and loyalty. This is also the subject of our empirical study. The results show that the proposed hybrid method is effective for innovative product/service development. Moreover, the empirical findings provide useful information for automobile maintenance providers so that they may be better able to pay attention to their competitive positions and their customers' preferences, and better able to facilitate their innovative automobile maintenance service development, in order to achieve sustainable competitive advantages.
\end{abstract}

Keywords: Positioning Analysis; Conjoint Analysis; Rough Set Theory; Automobile Maintenance

\section{Introduction}

According to the statistical data of the Ministry of Transportation and Communications, Taiwan (2012), there were $5,982,471$ registered passenger cars [1]. One out of four people in Taiwan owns a passenger car. Automobiles are consumer goods; the more they are used, the more maintenance is required, and the costs of usage continue to increase. Automobile maintenance services have become important sources of revenue for automobile dealers. Understandably, consumers take maintenance service into consideration when purchasing new cars. In Taiwan, consumers traditionally tend to choose their regional dealers as their maintenance service providers. However, due to keen competition, some customers have started to change their service providers and are choosing small automobile maintenance factories. They do this due to word-of-mouth recommendations, reasonable fees, and a variety of services $[2,3]$. Therefore, providing innovative maintenance services has become an important issue for maintenance service providers.
Innovation plays an important role in companies conducting transformation, and innovative activities bring great potential profit for the organization [4]. In [5], Weerawardena pointed out that innovation was the process of improving the production process, services, organizational system and marketing systems to create customer value. In [6], Danneels and Kleinschmidt suggested that product innovation had to separate the viewpoints of corporations from those of customers, as they had different perspectives regarding innovation. In [7], Kwaku indicated that from customers' viewpoints, a product's degree of novelty had a certain compatibility with the types of customers' consumption and experiences. Many scholars have worked on categorizing product and service innovation types [8-12]. According to their categorization, innovation can be divided into: continuous innovation, dynamically continuous innovation, discontinuous innovation, breakthrough, complementary innovation, incremental innovation, technological breakthrough innovation and market breakthrough innovation. 
The purpose of this study is to employ a hybrid method of positioning analysis, conjoint analysis and rough set theory and then to apply them to examine innovative automobile maintenance services, with the ultimate aim of improving service qualities and enhancing customers' satisfaction and loyalty. First, through indepth interviewing, we develop a questionnaire to investigate customers' degrees of satisfaction toward automobile maintenance service. Based on the results, we then conduct a factor analysis and preference regression to ascertain the automobile maintenance providers' competitive positions. Then, ideas simulation and selection are applied to determine customers' demands and develop a questionnaire of conjoint analysis. Through conjoint analysis, the most desired innovative service attributes and levels can be found out. Our aim is to provide useful information for the managers of the automobile maintenance industry so that they can understand their competitive positions and facilitate their innovative services' development. Finally, we apply rough set theory to carry out further customer-based conjoint data reduction and information retrieval.

This study is divided into five sections. Section 1 is the introduction. In Section 2, we introduce the research method applied in this study. In Section 3, the research procedure and data are illustrated, with the results given in Section 4. Section 5 provides conclusions along with suggestions for the future direction of innovative automobile maintenance service development.

\section{Literature Review}

\subsection{Positioning Analysis}

Positioning analysis is used to investigate a product's competitive position in relation to others and to explore the market position for new products. The purpose of conducting positioning analysis includes the discovery of new sales opportunities, repositioning and understanding the real competitive nature of markets. Positioning analysis can be used to determine a product's relative position, and can provide ideas to form a basis for the development of new products. Many scholars have used positioning analysis to investigate a product's competitive position and to explore a new product's potential market position [13-17].

\subsection{Conjoint Analysis}

Conjoint analysis can be adapted to understand the individual differences in terms of consumer characteristics related to demographics, attitudes, habits, etc; it can also be used for choice simulation and to determine the best designs $[18,19]$. The results of conjoint analysis can help marketers to have an improved understanding of consumers, and can provide important information for prod- uct development as well as for the development of good marketing strategies [20].

\subsection{Rough Set Theory}

Rough set theory is based on the assumption that information retrieval can be achieved with objects [21]; it is based on the use of theoretical mathematics to extract significant attributes or rules from data [22]. The fundamental rough set theory can be categorized as follows: first, let $K=(U, \mathrm{R})$ be a knowledge base [23]. Given a finite set $U \neq \varphi$, any subset $X \subseteq U$ of the universe is called a concept in $U$. Second, given a finite set $U \neq \varphi$, the universe of objects and a concept $X \subseteq U$, any family of concepts (or category) in $U$ is referred to as knowledge about $U$. Let $\mathrm{R}$ be an equivalence relation over $U$; then we can define $U / R$ as the family of all equivalence classes of $\mathrm{R}$, and let $[X]{ }_{\mathrm{R}}$ denote a concept in $\mathrm{R}$ containing an element $X \subseteq U$. Third, given $K=(U, \mathrm{R})$, if $P \subseteq R$ and $P \neq \varphi$, then there is an equivalence relation $\operatorname{IND}(P)$ called the indiscernibility relation over $P$.

In recent years, the rough set theory has been applied with other research methodologies in many areas to support decision making and the development of new products. In [24], Pattaraintakorn and Cercone incorporated the rough set theory for medical application. In [25], Shao et al. used rough set theory to aid the conceptual design of a ship's engine room automation. In [26], Shyng et al. applied an integration method combining rough set theory with formal concept analysis as research methods to conduct personal investment portfolio analyses.

\section{Research Procedure Using a Hybrid Method}

This study employs a hybrid method, including: positioning analysis, conjoint analysis and rough set theory to develop innovative automobile maintenance services, in order to improve service qualities and enhance customer satisfaction and loyalty.

In the positioning analysis phase, a questionnaire investigation was conducted based on the Likert-five-point scale. The questionnaire was developed based on the results of in-depth interviews and a literature review. There were 24 questions, including a question inquiring about the total degree of satisfaction which would become the dependent variable when conducting preference regression. We chose five representative automobile maintenance service providers as our research subjects: Mazda, Volkswagen, Toyota, Honda and a small automobile maintenance factory. They were chosen based on their numbers of registered vehicles, their reputations, market competitive power, and their willingness to co- 
operate with this research. There were 100 respondents, and a total of 500 questionnaires were released. Through this investigation, we were able to ascertain the respondents' degree of satisfaction toward service providers. We then analyzed the data through factor analysis and regression analysis to find the degree of importance of the various factors, and plotted perception maps.

In the conjoint analysis phase, followed by the results of the positioning analysis, we used ideas simulation and ideas selection to find customers' demands. After that, we used specific weight valuation for ideas selection based on the results of the factor analysis. We derived five attributes and assigned two levels for each attribute. We had five attributes and 10 levels in total. Next, we designed the conjoint analysis questionnaire and then conducted the questionnaire investigation. We launched 200 questionnaires by means of convenience sampling. The respondents were customers who had had automobile maintenance experiences. There were two parts to the questionnaire. The first was a conjoint card. We applied a perpendicular arrangement of SPSS software package to design the conjoint cards. A total of 10 conjoint cards were developed. We used both graphics and letters to enable the respondents to easily understand the contents of cards. Respondents were asked to rank the cards according to their preferences. The second part was concerned with an investigation into the demographic variables of the respondents, the purpose being to understand the relationships between customers' preferences and their demographic characteristics.

In the rough set theory analysis phase, we used ROSE software [27] to conduct the data reduction and information retrieval. We chose the respondents' first and second preference services as the data for analysis. By means of the analysis, we could determine the customers' preference rules toward the attributes.

\section{Results}

\subsection{Positioning Analysis}

We chose 10 customers who had had automobile maintenance experiences as the in-depth interview respondents; the interview was held during August, 2010. Our interviewees were good at communication, aggressive and coordinative. Based on the in-depth interviews and a literature review, we developed a questionnaire that would enable us to investigate the degree of customer satisfaction. The investigation was held during January, 2011 with 500 pieces, 100 pieces for each object. The respondents were customers of Mazda, Volkswagen, Toyota, Honda and small automobile maintenance factories. We collected 487 effective questionnaires. Through the investigation, we were able to determine the degree of satisfaction that customers had toward their automo- bile maintenance service providers. Questions related to satisfaction investigation are listed in Table 1.

After the investigation, we conducted a descriptive statistical analysis of the respondents' demographic variables and a factor analysis of the listed top 23 questions. We chose the "promax" rotation method to conduct a factor analysis since the factors are correlated to each other. There are some significant indicators for factor analysis. First, as far as the communality is concerned, if the variable's communality is smaller than 0.3 , then it makes little contribution to the analysis and the variable should be deleted. Second, if the factor's Eigen value is larger than 1, the factor analysis is reliable. Furthermore, if the factor loading absolute value is larger than 0.4 , the factor analysis is reliable. Finally, if the total accumulated factor loading absolute value is larger than $50 \%$, the explanation power is acceptable.

In the first promax rotation, we extracted three components, and the total accumulated factor loading absolute values were $55.859 \%$. Bartlett's test of sphericity was significant, approximate to 0 , and the $\mathrm{KMO}$ value was 0.933. Screening the communalities and its factor loading, all variables were larger than 0.3 , and the factor loading was larger than 0.4 . Therefore, no variables were deleted. We named the three components as considerate services, professional attitude and comfortable environment.

Then, we applied preference regression in order to plot the perception map. The independent variables are the three components' factor scores, and the dependent vari-

Table 1. Questions of satisfaction investigation.

\begin{tabular}{l} 
Questions \\
\hline 1) Service attitudes of reception personnel \\
2) Professional ability of reception personnel \\
3) Service attitudes of technicians \\
4) Professional ability of technicians \\
5) Maintenance completion in time \\
6) Environment cleanness of working area \\
7) Environment cleanness of waiting area \\
8) Satisfactory degree of component's quality \\
9) Thoroughness of components \\
10) Transparency cost of components and wages \\
11) Regularly informing promotion projects \\
12) Regularly informing maintenance necessities \\
13) Other sweet services (ex. Free car wash service) \\
14) Satisfactory degree of promotion projects \\
15) Detailed instruction of maintenance items and cost \\
16) Density of automobile maintenance factories \\
17) Convenience access to the factory \\
18) Total maintenance solutions for customers' demands \\
19) Maintenance reservation service \\
20) After service concern \\
21) Internet reservation service and inquiry service of maintenance \\
record \\
22) Insurance consultant and re-insurance informing \\
23) Other peripheral products selling services \\
24) Total Satisfactory degree \\
\hline
\end{tabular}


able was question 24, the total degree of satisfaction of all respondents. According to preference regression, the $P$ value of all items was significant, and the standardized beta values of three components were: $0.541,0.417$ and 0.112 , as presented in Table 2 .

According to the component's value of Standardized Beta, we could derive the degrees of the $\mathrm{X}$ and $\mathrm{Y}$ axes. The way to compute the degree of axis is $\mathrm{A} /(\mathrm{A}+\mathrm{B})$. A and $\mathrm{B}$ are represented for components' standardized beta value. Moreover, each automobile maintenance service provider's position was derived from their average factor scores from the factor analysis. The average factor scores of each provider are shown in Table 3.

We proceeded to plot the perception maps. First we created the map of considerate services and professional attitude components. The degree of axis of considerate services component was:

$$
0.541 /(0.541+0.417)=0.565
$$

whereas professional attitude component was:

$$
0.417 /(0.541+0.417)=0.435 \text {. }
$$

The derived numerals presented the ideal vector. Then, the five companies' average scores were added into the map. The competitive position of automobile maintenance service providers can be realized. Honda and Toyota had better competitive advantages, whereas Mazda, Volkswagen and small automobile maintenance factories showed the need to enhance their customer satisfaction.

Second was the map detailing the considerate services and comfortable environment components. The degree of axis of considerate services component was:

Table 2. Regression coefficients.

\begin{tabular}{cccccc}
\hline \multirow{2}{*}{ Model } & \multicolumn{2}{c}{$\begin{array}{c}\text { Unstandardized } \\
\text { Coefficients }\end{array}$} & $\begin{array}{c}\text { Standardized } \\
\text { Coefficients }\end{array}$ & \multirow{2}{*}{ T } & Significance \\
\cline { 2 - 4 } & $\beta$ & Std. Error & Beta & & \\
\hline constant & 3.468 & 0.021 & & 168.503 & 0.000 \\
Component 1 & 0.426 & 0.030 & 0.541 & 14.374 & 0.000 \\
Component 2 & 0.329 & 0.031 & 0.417 & 10.611 & 0.000 \\
Component 3 & 0.090 & 0.029 & 0.112 & 3.055 & 0.002 \\
\hline
\end{tabular}

Table 3. Average factor scores.

\begin{tabular}{cccc}
\hline Companies & $\begin{array}{c}\text { Considerate } \\
\text { services }\end{array}$ & $\begin{array}{c}\text { ProfessionalComfortable } \\
\text { attitude }\end{array}$ & $\begin{array}{c}\text { environment } \\
\text { Volkswagen }\end{array}$ \\
Toyota & 0.004376 & -0.188320 & -0.163432 \\
Honda & 0.073695 & -0.043760 & -0.016830 \\
Mazda & 0.314075 & 0.245682 & 0.289840 \\
Small automobile maintenance & -0.211790 & 0.155252 & 0.051058 \\
Factories Volkswagen & & & \\
\hline
\end{tabular}

$$
0.541 /(0.541+0.112)=0.828
$$

while the degree of axis of comfortable environment was:

$$
0.112 /(0.541+0.112)=0.172
$$

The following steps were as mentioned above. Wwe realized that Mazda was in the weakest position compared to all the other competitors. Honda, on the other hand, had the best performance, followed by Toyota. Volkswagen and small automobile maintenance factories were shown to need to improve themselves in at least one component direction.

Finally was the map of professional attitudes and comfortable environment components. The degree of axis of professional attitudes was:

$$
0.417 /(0.417+0.112)=0.788
$$

while the degree of axis of comfortable environment was:

$$
0.112 /(0.417+0.112)=0.212 \text {. }
$$

We realized that Honda and small automobile maintenance factories had better positions. Volkswagen and Mazda were both in weaker positions.

Above all, through positioning analysis, we realized that Honda had the best competitive position in all three components, followed by Toyota and small automobile maintenance factories. Volkswagen and Mazda were in weaker competitive positions. It can be seen that Honda can be the benchmark for other providers and, as such, is the top competitor.

\subsection{Conjoint Analysis}

Following on from the results of the positioning analysis, we used the three critical components' specific weights derived from regression analysis as valuation items to perform ideas simulation and ideas selection. We developed innovative automobile maintenance services which included five attributes, with each one having 2 levels, for a total of 10 levels, as Table 4 shows.

We applied a perpendicular arrangement of the SPSS software [28] to design 10 conjoint cards. We conducted the questionnaire investigation with 200 customers during March and April, 2010. Our respondents were experienced automobile maintenance customers. The effective questionnaires totaled 192.

\subsubsection{The Preference of Total Respondents}

According to the results of the conjoint analysis, Kendall's tau value was 0.929 , which is larger than 0.5 . We could conclude that the analysis has high consistency, and is reliable. The preference of total respondents is shown in Table 5. 
Table 4. Attributes and levels of innovative automobile maintenance services.

\begin{tabular}{|c|c|}
\hline Attribute & Level \\
\hline $\begin{array}{l}\text { A. Mobility } \\
\text { maintenance } \\
\text { services }\end{array}$ & $\begin{array}{l}\text { A1. Service personnel drive customers' } \\
\text { automobile to the maintenance factory } \\
\text { A2. Home maintenance services through } \\
\text { mobility maintenance vehicle }\end{array}$ \\
\hline $\begin{array}{l}\text { B. E-surveying } \\
\text { system }\end{array}$ & $\begin{array}{l}\text { B1. Computer equipped in the maintenance } \\
\text { waiting area for customer's to survey their } \\
\text { maintenance information } \\
\text { B2. Maintenance information to be } \\
\text { surveyed through corporate website }\end{array}$ \\
\hline $\begin{array}{l}\text { C.E-monitoring } \\
\text { system }\end{array}$ & $\begin{array}{l}\text { C1. Monitor equipped in the maintenance } \\
\text { waiting area for customer's to watch the } \\
\text { dynamic maintenance scene } \\
\text { C2. Internet video provided for customer's } \\
\text { to watch the maintenance scene }\end{array}$ \\
\hline $\begin{array}{l}\text { D. Standardized } \\
\text { operation } \\
\text { procedure }\end{array}$ & $\begin{array}{l}\text { D1. Intensive training toward personnel } \\
\text { D2. Standard operation procedure } \\
\text { development, ex. Brochure }\end{array}$ \\
\hline $\begin{array}{l}\text { E. Identification } \\
\text { and authorization }\end{array}$ & $\begin{array}{l}\text { E1. Support small automobile maintenance } \\
\text { factories to pass the identification of the } \\
\text { original automobile makers. } \\
\text { E2. Franchise authorization and resource } \\
\text { sharing from the automobile makers to } \\
\text { small automobile maintenance factories }\end{array}$ \\
\hline
\end{tabular}

Table 5. Preference of total respondents.

\begin{tabular}{ccccc}
\hline Attribute & $\begin{array}{c}\text { Importance } \\
(\%)\end{array}$ & $\begin{array}{c}\text { Preference } \\
\text { order }\end{array}$ & Level & utility \\
\hline A. & 22.7 & 3 & A1. & 0.188 \\
& & & A2. & -0.188 \\
B. & 40.7 & 1 & B1. & 0.337 \\
& & & B2. & -0.337 \\
C. & 7.0 & 4 & C1. & -0.058 \\
& & & C2. & 0.058 \\
D. & 6.6 & 5 & D1. & 0.054 \\
& & & D2. & -0.054 \\
E. & 23.0 & 2 & E1. & -0.191 \\
Sum & 100 & & E2. & 0.191 \\
& & & &
\end{tabular}

From Table 5, we realized the preference ranking of total respondents: e-surveying system (40.7\%), identification and authorization (23.0\%), mobility maintenance services $(22.7 \%)$, e-monitoring system $(7.0 \%)$ and standardized operation procedure $(6.6 \%)$. The degrees of preferences of total respondents were: A1. service personnel drive customer's automobile to the maintenance factory; B1. computer equipped maintenance waiting area for customers to survey their maintenance information; C2. internet video provided for customers to watch the maintenance scene; D1. thorough training for personnel and, E2, franchise authorization and resource sharing from automobile makers to small automobile maintenance factories.

\subsubsection{The Preference Differences among Different Demographic Variables}

To determine the preference differences among demographic variables, we conducted a conjoint analysis according to different demographic variables. The preference portfolios among all respondents, regardless of gender, or age are almost the same. It shows that most respondents had the same preferences toward innovative automobile maintenance services. This could be useful information for services providers, in helping them to avoid resource waste.

\subsection{Rough Set Analysis}

While conducting the conjoint analysis, we collected 192 effective questionnaires. We used software to process the conjoint data reduction and information retrieval. We chose the respondents' first and second preference conjoint cards as the data for analysis. Through the analysis, we could find out the customers' preference rules toward the attributes.

The first and second preference data totaled 384 . The customers' attribute preferences are presented in Table 6. It is worthwhile mentioning that the preference levels of attributes that we derived from the rough set analysis are all the same as the levels which we derived from the conjoint analysis. It proves the consistency and accuracy of our analysis.

We used rule 1 and rule 2 to give explanations. Rule1 represents A1: service personnel drive customers' automobiles to the maintenance factory. The sum of the selected respondents was 220 , and the percentage was $57.29 \%$ (220/384). Rule2 represents A2: home maintenance services by means of mobility maintenance vehicles. The sum of selected respondents was 164, and the percentage was $42.71 \%(164 / 384)$. The results can provide automobile maintenance service providers with more specific preference structures and support their decision making in planning innovative automobile maintenance services.

Table 6. Decision rules of respondents.

\begin{tabular}{ccccc}
\hline $\begin{array}{c}\text { Decision } \\
\text { rule }\end{array}$ & Attribute & $\begin{array}{c}\text { Level of } \\
\text { attribute }\end{array}$ & $\begin{array}{c}\text { Number } \\
(\%)\end{array}$ & Preference \\
\hline rule 1 & A. & A1. & $220(57.29 \%)$ & $※$ \\
rule 2 & A2. & $164(42.71 \%)$ & \\
rule 3 & B. & B1. & $173(45.05 \%)$ & \\
rule 4 & & B2. & $211(54.95 \%)$ & $※$ \\
rule 5 & C. & C1. & $140(36.46 \%)$ & \\
rule 6 & & C2. & $244(63.54 \%)$ & $※$ \\
rule 7 & D. & D1. & $136(35.42 \%)$ & \\
rule 8 & & D2. & $248(64.58 \%)$ & $※$ \\
rule 9 & E. & E1. & $188(48.96 \%)$ & \\
rule 10 & & E2. & $196(51.04 \%)$ & $※$ \\
\hline
\end{tabular}




\section{Managerial Implications}

The key managerial implications of this study are highlighted by the following issues. First, when developing new products/services, it is important to heed the customers' needs and voices. Take the consumer electronic product industry as an example; the Japanese manufactures, Sony, NEC and Matsushita had strong technical advantages, however, their lack of competition with competitors, lack of innovative products and failure to listen to customers' voices led to their inferior performance. Our hybrid method is a useful tool for manufactures and service providers to realize their market positions and to plan innovative products/services.

Second, from our empirical positioning analysis results of the automobile maintenance industry in Taiwan, we realize that Honda has the best competitive position, followed by Toyota and then by the small automobile maintenance factories. Volkswagen and Mazda are in weaker competitive positions. Honda can be seen as the other providers' benchmark and certainly is the top competitor. The automobile maintenance industry is a dynamically competitive market. Customers can easily change their service provider to small automobile maintenance without switching cost. Moreover, customers may change their purchasing brand due to dissatisfaction with automobile dealer's maintenance services. It is very important for automobile maintenance dealers to enhance customer satisfaction, and innovative services are indispensable in that regard.

Third, from our empirical conjoint analysis results, we realized the preference ranking of total respondents: esurveying system $(40.7 \%)$, identification and authorization $(23.0 \%)$, mobility maintenance services $(22.7 \%)$, e-monitoring system $(7.0 \%)$ and standardized operation procedure $(6.6 \%)$. The preferences of the total respondents were: A1. service personnel drive customers' automobiles to the maintenance factory; B1. computer equipped maintenance waiting areas for customers to survey their maintenance information; $\mathrm{C} 2$. internet video provided for customers to watch the maintenance scene; D1. intensive training of personnel, and E2. franchise authorization and resource sharing from automobile makers to small automobile maintenance factories. The results provide the automobile maintenance providers with useful information for the development of new services.

Fourth, the results of the rough set analysis can provide automobile maintenance service providers with more specific preference structures, and can support their decision making in planning innovative automobile maintenance services.

Finally, our empirical research findings can provide useful information not only for Taiwan's but also China's automobile industry. Taiwan and China share the same racial backgrounds, traditions, ideologies and languages. Therefore, Taiwan has long been seen as a reference market for consumer behavior and new product/service development for China. Furthermore, Taiwan's industry has gradually increased investment, joint ventures and strategic alliance strategies with China's industry. Those are the reasons why our research can provide useful information for both Taiwan and China's automobile maintenance industry.

\section{Conclusions}

This study introduced a hybrid method of positioning analysis, conjoint analysis and rough set theory to indicate competitive positions and facilitate innovative product/service development from customers' viewpoints. The approach was supported by in-depth interviews, factor analyses, preference regression, ideas simulation, ideas selection and specific weight valuation methods. Through the conducting of this empirical study dealing with the automobile maintenance industry in Taiwan, the effectiveness of the proposed approach is demonstrated. Furthermore, the research findings provide useful information for automobile maintenance service providers to understand their competitive positions and customers' preferences and, thus, facilitate their development of innovative services to enhance customers' satisfaction and loyalty.

The study has suggested two further studies. First, our suggested hybrid method can be applied by company experts in new product/service development to perform a more thorough investigation, given sufficient time and financial resources. Future studies can select more competitors as research objects and involve more respondents in order to get more detailed information. Second, it will be worthwhile for company experts to attend to the investigation of innovative product/service needs from customers' points of view, and integrate their findings into new product/service development. To that purpose, quality deployment function methodology can be integrated into our proposed hybrid method. By applying the proposed approach, experts of companies can derive effective and meaningful analyses, thus enabling companies to achieve a sustainable competitive advantage.

\section{Acknowledgements}

This study is supported by the Department of Research and Development, Ming Dao University, and the National Science Council of Taiwan, Republic of China, under grant number NSC 101-2410-H-451-002.

\section{REFERENCES}

[1] C. Lee and P. Linneman, "Number of Registered Motor 
Vehicles," Ministry of Transportation and Communications, 2012.

[2] T. S. Jan and C. T. Hsiao, "A Four-Role Model of the Automotive Industry Development in Developing Countries: A Case in Taiwan," Journal of the Operational Research Society, Vol. 55, No. 11, 2004, pp. 1145-1155. http://dx.doi.org/10.1057/palgrave.jors.2601776

[3] L. L. Tang and T. S. Chuang, "Applying Kano Model to Develop Quality Function of Automobile Facilities," Journal of Management, Vol. 21, No. 3, 2004, pp. 311-330.

[4] M. Kotabe, "Corporate Product Policy and Innovative Behavior of European and Japanese Multinationals: An Empirical Investigation," Journal of Marketing, Vol. 54, No. 2, 1990, pp. 19-33. http://dx.doi.org/10.2307/1251867

[5] J. Weerawardena, "The Role of Marketing Capability in Innovation-Based Competitive Strategy," Journal of Strategy Marketing, Vol. 11, No. 1, 2003, pp. 15-35. http://dx.doi.org/10.1080/0965254032000096766

[6] E. Danneels and E. J. Kleinschmidt, "Product Innovativeness from the Firm's Perspective: Its Dimensions and Their Relation with Project Selection and Performance," Journal of Product Innovation Management, Vol. 18, No. 6, 2001, pp. 357-373. http://dx.doi.org/10.1016/S0737-6782(01)00109-6

[7] A. Kwaku, "Market Orientation and Innovation," Journal of Business Research, Vol. 35, No. 2, 1996, pp. 93-104. http://dx.doi.org/10.1016/0148-2963(95)00051-8

[8] Y. Wind and V. Mahajan, "Issues and Opportunities in New Product Development: An Introduction to the Special Issue," Journal of Marketing Research, Vol. 34, No. 1, 1997, pp. 1-12. http://dx.doi.org/10.2307/3152060

[9] X. M. Song and J. Xie, "Does Innovativeness Moderate the Relationship between Cross-Functional Integration and Product Performance?" Journal of International Marketing, Vol. 8, No. 4, 2000, pp. 61-89.

http://dx.doi.org/10.1509/jimk.8.4.61.19796

[10] U. Brentani, "Innovative versus Incremental New Business Services: Different Keys for Achieving Success," Journal of Product Innovation Management, Vol. 18, No. 3, 2001, pp. 169-187.

http://dx.doi.org/10.1016/S0737-6782(01)00071-6

[11] R. Garcia and R. Calantone, "A Critical Look at Technological Innovation Typology and Innovativeness Terminology: A Literature Review," Journal of Product Innovation Management, Vol. 19, No. 2, 2002, pp. 110-132. http://dx.doi.org/10.1016/S0737-6782(01)00132-1

[12] M. J. Benner and M. L. Tushman, "Exploitation, Exploration, and Process Management: The Productivity Dilemma Revisited," Academy of Management Review, Vol. 28, No. 2, 2003, pp. 238-256.

[13] P. E. Green and A. M. Krieger, "An Application of a Product Positioning Model to Pharmaceutical Products," Marketing Science, Vol. 11, No. 2, 1992, pp. 117-132. http://dx.doi.org/10.1287/mksc.11.2.117

[14] C. S. Whan, W. S. DeSarbo and P. T. Harker, "Product Positioning under Price Competition," Management Sci- ence, Vol. 36, 1990, pp. 175-199.

[15] J. S. Chen and M. Uysal, "Market Positioning Analysis: A Hybrid Approach," Annals of Tourism Research, Vol. 29, No. 4, 2002, pp. 987-1003. http://dx.doi.org/10.1016/S0160-7383(02)00003-8

[16] E. Haezendonck, A. Verbeke and C. Coeck, "Strategic Positioning Analysis for Seaports," Research in Transportation Economics, Vol. 16, 2006, pp. 141-169. http://dx.doi.org/10.1016/S0739-8859(06)16007-2

[17] S. C. Carlos, F. C. Yolanda and G. N. Begoña, "Internet Positioning and Performance of E-Tailers: An Empirical Analysis," Electronic Commerce Research and Applications, Vol. 9, No. 3, 2010, pp. 237-248. http://dx.doi.org/10.1016/j.elerap.2009.09.001

[18] R. G. Biesma, M. Pavlova, M. G. G. Van and W. Groot, "Using Conjoint Analysis to Estimate Employers Preferences for Key Competencies of Master Level Dutch Graduates Entering the Public Health Field," Economics of Education Review, Vol. 26, No. 3, 2007, pp. 375-386. http://dx.doi.org/10.1016/j.econedurev.2006.01.004

[19] S. Y. Sohn and Y. H. Ju, "Conjoint Analysis for Recruiting High Quality Students for College Education," Expert Systems with Applications, Vol. 37, No. 5, 2010, pp. 3777 3783. http://dx.doi.org/10.1016/j.eswa.2009.11.043

[20] I. Endrizzi, E. Menichelli, S. B. Johansen, N. V. Olsen and T. Naes, "Handling of Individual Differences in Rating-Based Conjoint Analysis," Food Quality and Preference, Vol. 22, No. 3, 2011, pp. 241-254.

http://dx.doi.org/10.1016/j.foodqual.2010.10.005

[21] Z. Pawlak, "Rough Sets," International Journal of Information and Computer Sciences, Vol. 11, 1982, pp. 341356. http://dx.doi.org/10.1007/BF01001956

[22] P. Pattaraintakorna and N. Cerconeb, "A Foundation of Rough Sets Theoretical and Computational Hybrid Intelligent System for Survival Analysis," Computers and Mathematics with Applications, Vol. 56, 2008, pp. 1699 1708. http://dx.doi.org/10.1016/j.camwa.2008.04.030

[23] Z. Pawlak, "Rough Set: Theoretical Aspects of Reasoning about Data," Kluwer Academic Publishers, Dordrecht. 1991.

[24] P. Pattaraintakorna and N. Cerconeb, "Integrating Rough Set Theory and Medical Applications," Applied Mathematics Letters, Vol. 21, No. 4, 2008, pp. 400-403. http://dx.doi.org/10.1016/j.aml.2007.05.010

[25] X. Y. Shao, X. Z. Chu, H. B. Qiu, L. Gao and J. Yan, “An Expert System Using Rough Sets Theory for Aided Conceptual Design of Ship's Engine Room Automation," Expert Systems with Applications, Vol. 36, No. 2, 2009, pp. 3223-3233. http://dx.doi.org/10.1016/j.eswa.2008.01.011

[26] J. Shyng, H. Shieh and G. Tzeng, “An Integration Method Combining Rough Set Theory with Formal Concept Analysis for Personal Investment Portfolios," KnowledgeBased Systems, Vol. 23, No. 6, 2010, pp. 586-597. http://dx.doi.org/10.1016/j.knosys.2010.04.003

[27] B. Predki, R. Slowinski, J. Stefanowski, R. Susmaga and S. Wilk, "ROSE-Software Implementation of the Rough Set Theory," In: L. Polkowski and A. Skowron, Eds., Rough Sets and Current Trends in Computing, Proceed- 
ings RSCTC'98, Lecture Notes in Artificial Intelligence, Vol. 1424, 1998, pp. 605-608.
[28] A. Field, "Discovering Statistics Using SPSS," 3rd Edition, SAGE, Los Angeles, 2009. 